Jurnal Pemberdayaan: Publikasi Hasil Pengabdian kepada Masyarakat

Vol. 4, No. 3, Desember 2020, Hal. 245-250

ISSN: 2580-2569; e-ISSN: 2656-0542

DOI: https://doi.org/10.12928/jp.v4i3.2794

\title{
Pemanfaatan Sosial Media untuk Digital Marketing Bagi Anak Berkebutuhan Khusus di SLB B Yakut Purwokerto
}

\author{
Anisa Nur Andina, Esa Fatimatuz Zahra, Misbakhul Munirruddin \\ Universitas Amikom Purwokerto, Jl. Letjend Pol. Soemarto, Watumas, Purwanegara, Kec. \\ Purwokerto Utara, Kabupaten Banyumas, Jawa Tengah \\ Email: andina@amikompurwokerto.ac.id
}

\begin{abstract}
ABSTRAK
Program pengabdian kepada masyarakat yang mengangkat tema pemanfaatan sosial media untuk digital marketing bagi anak berkebutuhan khusus. Progran ini bertujuan untuk mengakomodasi dan melatih anak berkebutuhan khusus untuk melakukan digital marketing terhadap produk yang telah mereka hasilkan. Kegiatan pengabdian kepada masyarakat ini dilaksanakan dalam dua kegiatan yaitu pelatihan dan pendampingan. Pelatihan yang dilakukan adalah pelatihan mengambil foto serta pelatihan menggunakan sosial media untuk melakukan digital marketing secara baik dan benar. Faktor pendukung kegiatan ini adalah adanya kerjasama yang baik dari pihak SLB B Yakut Purwokerto sehingga segala yang sudah direncanakan dapat berjalan dengan lancar, sedangkan untuk faktor penghambatnya tidak ada. Kesimpulan dari pelaksanaan program pengabdian kepada masyarakat ini adalah meningkatnya pengetahuan dan pemahaman terhadap digital marketing untuk anak berkebutuhan khusus yang dapat membantu dalam memasarkan produk yang telah dihasilkan.
\end{abstract}

Kata kunci: Anak berkebutuhan khusus, Digital marketing, Sosial media

\section{ABSTRACT}

Community service program with the theme of using social media for digital marketing for children with special needs. This program aims to accommodate and train children with special needs to do digital marketing of the products they have produced. This community service activity is carried our in two activities, namely training and mentoring. The training carried out is training for taking photos and training on using social media to do digital marketing properly. The supporting factor for this activity is the existence of good cooperation from SLB $B$ Yakut Purwokerto so that everything that has been planned can run smoothly, while there is no inhibing factor here. The conclusion from the implementation of this community service program is the increased knowledge and understanding of digital marketing for children with special needs that can help them in marketing the products that have been produced.

Keywords: children with special needs, digital marketing, social media

\section{PENDAHULUAN}

Istilah anak berkebutuhan khusus secara eksplisit ditujukan kepada anak yang dianggap mempunyai kelainan/penyimpangan dari kondisi rata-rata anak normal umumnya, dalam hal fisik, mental maupun karakteristik perilaku sosialnya (Efendi, 2006). Menurut klasifikasi dan jenis kelainan anak berkebutuhan khusus di kelompokkan ke dalam kelainan fisik, kelainan mental dan kelainan perilaku sosial.

Kelainan fisik adalah kelainan yang terjadi pada satu atau lebih organ tubuh tertentu akibat kelainan tersebut timbul suatu keadaan pada fungsi tubuhnya dimana tidak bisa menjalankan tugasnya secara normal. Misalnya kelainan pada pendengaran (tunarungu), 
penglihatan (tunanetra), maupun pada organ bicaranya (tunawicara) serta banyak kelainan yang lain.

Kelainan mental adalah anak yang memiliki penyimpangan kemampuan berpikir secara kritis, logis dalam menanggapi dunia sekitarnya. Dalam kelainan mental dapat menyebar ke dua arah yaitu kelainan mental dalam arti lebih (supernormal) dan kelainan mental dalam arti kurang (subnormal). Kelainan mental dalam arti lebih atau anak unggul dapat dikelompokkan menjadi anak mampu belajar dengan cepat, anak berbakat, dan anak genius. Karakteristik mereka pada umumnya adalah tingkat kecerdasannya yang berada pada rentang 110 hingga diatas 140. Sementara anak yang kurang atau tunagrahita adalah anak yang diidentifikasi mempunyai tingkat kecerdasan yang sedemikian rendahnya atau dibawah normal.

Kelainan perilaku sosial adalah anak yang mengalami kesulitan untuk menyesuaikan diri terhadap lingkungan, tata tertib, norma sosial dan lain-lain. Anak yang termasuk dalam kategori kelainan perilaku sosial adalah anak yang mempunyai tingkah laku yang tidak sesuai dengan adat yang berlaku di rumah, sekolah maupun di masyarakat sekitarnya.

WHO menyatakan bahwa lebih dari $5 \%$ populasi dunia atau 466 juta orang mengalami gangguan pendengaran, 34 juta diantaranya adalah anak-anak. Selanjutnya seseorang dengan gangguan pendengaran ringan, sedang, berat, atau dalam. Ini dapat mempengaruhi satu telinga atau keduanya dan menyebabkan kesulitan dalam mendengar percakapan. Anak berkebutuhan khusus dengan gangguan pendengaran biasanya berkomunikasi melalui bahasa isyarat serta alat bantu lainnya seperti teks. Pada SLB B Yakut Purwokerto berfokus pada siswa tunarungu.

Hallahan, dkk (2009) menjelaskan bahwa disabilitas diartikan sebagai ketidakmampuan untuk melakukan sesuatu seperti yang dilakukan orang lain. Selain itu disabilitas bisa dikatakan sebagai kehilangan fungsi fisik atau kesulitan dalam belajar serta penyesuaian sosial yang sangat berpengaruh terhadap pertumbuhan dan perkembangan.

Sementara untuk tunarungu sendiri menurut Hallahan, dkk (2009) adalah seseorang yang mempunyai kesulitan mendengar suara pada atau di atas intensitas tertentu. Tunarungu dapat muncul sejak lahir atau setelah kelahiran dengan berbagai penyebab.

Menurut pasal 15 UU No. 20 tahun 2003 tentang Sisdiknas bahwa jenis pendidikan bagi anak berkebutuhan khusus adalah Pendidikan Khusus. Pasal 32 (1) UU No. 20 tahun 2003 memberikan batasan bahwa pendidikan khusus merupakan pendidikan bagi peserta didik yang memiliki tingkat kesulitan dalam mengikuti proses pembelajaran karena kelainan fisik, emosional, mental, sosial, dan/atau memiliki potensi kecerdasan dan bakat istimewa.

Dalam hal ini layanan pendidikan khusus bagi siswa yang memiliki kebutuhan khusus diselenggarakan secara inklusif atau berupa satuan pendidikan khusus pada tingkat pendidikan dasar dan menengah. Jadi pendidikan khusus sementara hanya tersedia pada pendidikan dasar dan menengah.

Digital marketing dirasa cukup mampu untuk mengakomodir kemampuan anak berkebutuhan khusus dalam menjual produk yang mereka hasilkan. Digital marketing tidak membutuhkan tempat untuk berjualan sehingga lebih memudahkan mereka. Dengan bermodalkan smartphone, anak berkebutuhan khusus pun bisa memasarkan produk mereka dengan baik. SLB B Yakut memiliki banyak sekali anak berkebutuhan khusus dengan potensi yang luar biasa. Beberapa diantaranya memiliki keahlian membatik, membuat kerajinan tangan seperti dompet dan lainnya.

\section{METODE}

Metode yang dilakukan adalah pendampingan. Pendampingan dalam hal ini mencakup pendampingan dan pemanfaatan teknologi sebagai sarana untuk melakukan digital marketing hasil kerajinan siswa SLB B Yakut Purwokerto. Diawali dengan menganalisis kebutuhan untuk mengetahui apa yang dibutuhkan oleh mitra menggunakan cara observasi. 
Tahapan yang kedua adalah tahap persiapan. Pada tahap ini dilakukan persiapan dengan koordinasi dengan Kepala Sekolah dan Guru SLB B Yakut Purwokerto.

Setelah selesai tahap persiapan, dilanjutkan dengan tahap pelaksanaan. Tahap ini merupakan tahap yang paling penting dari semua tahapan. Diawali dengan pendahuluan. Pendahuluan dilakukan dengan memberikan penjelasan tentang digital marketing yang dibutuhkan oleh siswa SLB B Yakut dan alasan mengapa hal itu dibutuhkan. Selanjutnya dilakukan pelatihan mendaftar pada sosial media. Sosial media yang digunakan adalah Instagram yang saat ini lebih luas menjangkau semua kalangan untuk berbisnis. Pemilihan Instagram sebagai sarana bisnis karena saat ini Instagram memiliki banyak pengguna aktif yang selalu mengakses dan tentu saja mudah dalam penggunaannya untuk anak-anak berkebutuhan khusus. Anak-anak diajarkan untuk membuat sebuah akun dengan nama yang menarik dan tidak lupa untuk mencantumkan contact person supaya saat calon pembeli ingin menghubungi, tidak mengalami kesulitan.

Tahap selanjutnya adalah mengajarkan anak-anak untuk mengambil foto yang dapat menarik perhatian calon pembeli. Penggunaan kamera smartphone yang dapat memudahkan anak-anak berkebutuhan khusus menggunakannya. Selain menggunakan kamera smartphone, dilatih juga penggunaan alas foto supaya foto terlihat lebih hidup.

Lalu dilanjut dengan mengunggah hasil foto ke Instagram. Anak-anak diajarkan cara menulis caption supaya menarik perhatian calon pembeli. Caption diberi hashtag yang sedang populer supaya lebih cepat menemukan calon pembeli.

Tahapan terakhir adalah tahapan evaluasi. Peserta diberikan tugas untuk membuat sendiri akun Instagram dan mengambil foto dengan menggunakan alas foto. Setelah foto diambil mereka diberikan tugas lanjutan untuk mengunggah ke Instagram.

\section{HASIL, PEMBAHASAN, DAN DAMPAK}

Digital marketing sudah biasa dilakukan dan dipelajari oleh mereka yang bukan penyandang disabilitas tetapi ini merupakan sesuatu yang baru bagi mereka penyandang disabilitas. Pelatihan ini mendapat apresiasi yang baik dari siswa penyandang tunarungu SLB B Yakut Purwokerto. Pelaksanaan kegiatan ini dilakukan di laboratorium broadcasting dengan menerapkan protokol kesehatan dan keamanan covid-19 yang sangat ketat.

Pelatihan ini dimulai saat fasilitator datang untuk melakukan perkenalan serta analisis permasalahan pada SLB B Yakut Purwokerto (Gambar 1). Pihak SLB B Yakut Purwokerto menyambut dengan baik pelatihan ini karena sampai saat ini belum pernah diadakan pelatihan digital marketing untuk anak berkebutuhan khusus.

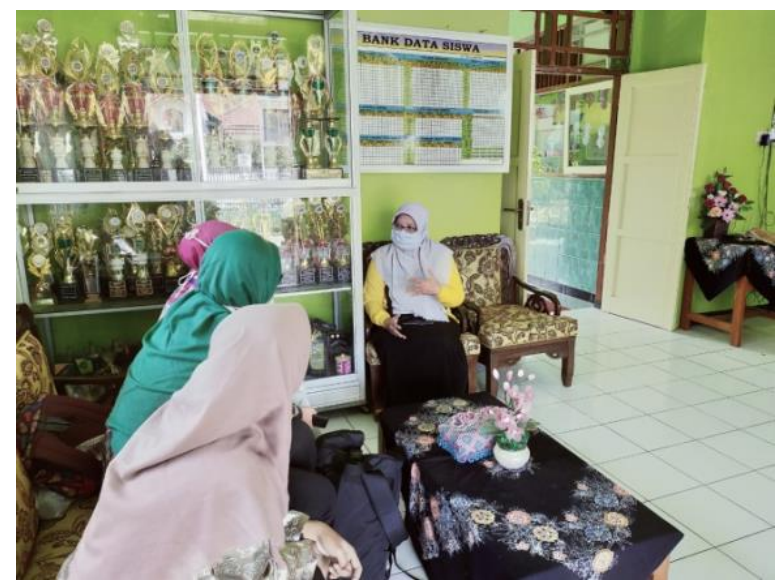

Gambar 1. Fasilitator melakukan kunjungan sekaligus melakukan analisis permasalahan pada SLB B Yakut Purwokerto. 
Pelatihan dilanjutkan pada tanggal 27, 28 dan 31 Agustus 2020. Fasilitator menjelaskan apa itu digital marketing dan manfaatnya bagi peserta. Peserta memperhatikan dengan seksama penjelasan dari guru dan membaca teks yang tertulis pada power point yang disajikan oleh fasilitator. Penggunaan media power point dengan teks dan gambar memudahkan peserta untuk lebih memahami yang dijelaskan oleh fasilitator (Gambar 2).

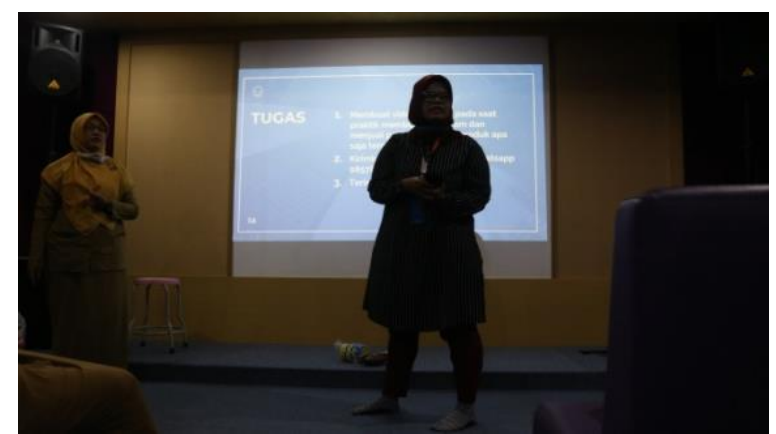

Gambar 2. Fasilitator memberikan penjelasan dibantu Guru SLB B Yakut Purwokerto sebagai penerjemah.

Fasilitator memberikan pengarahan dibantu oleh Guru SLB B Yakut Purwokerto sebagai penerjemah. Peserta yang merupakan siswa-siswa tunarungu mendengarkan dengan antusias segala penjelasan dari fasilitator. Hal ini membuat suasana pelatihan menjadi hidup. Pelatihan dilanjutkan dengan peserta mencoba sendiri mengambil foto dengan menggunakan alas foto didampingi oleh fasilitator (Gambar 3). Antusias peserta semakin meningkat setelah mengetahui bahwa alas foto itu bisa digunakan dengan sangat baik dan memperindah foto.

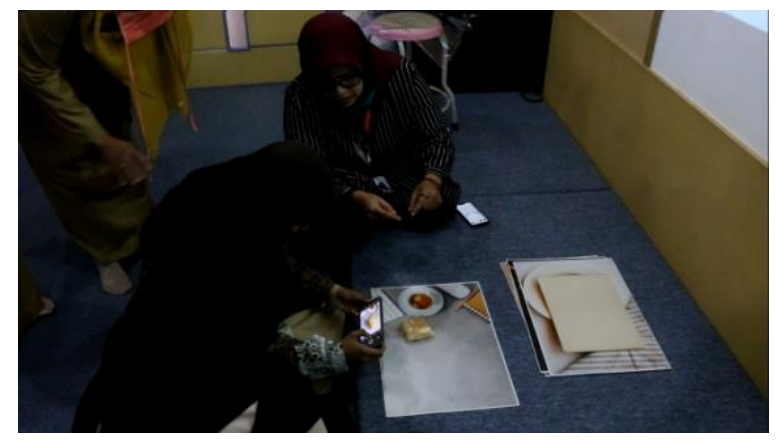

Gambar 3. Fasilitator memberikan pengarahan cara menggunakan alas foto dan cara mengambil foto.

Peserta pelatihan sangat menikmati acara pelatihan karena ini merupakan sesuatu yang baru. Mendapatkan pelajaran baru tentang digital marketing membuat peserta mengikuti pelatihan dengan antusias. Semua peserta dapat mencoba pada saat pelatihan.

Fasilitator yang terdiri dari dosen dan dua mahasiswa memberikan pengarahan dalam hal pencahayaan. Saat pengambilan foto, pencahayaan menjadi sangat penting agar hasil foto lebih maksimal. Proses pengambilan foto menggunakan alas foto juga membuat peserta takjub karena selama ini mereka kebingungan untuk mengambil foto dengan latar belakang yang baik. Peserta biasanya mengambil foto dengan latar belakang lantai sehingga hasilnya kurang maksimal. Alas foto diperkenalkan untuk lebih memperindah foto dengan harga yang terjangkau dan dapat didapatkan dengan mudah di mana saja.

Setelah dilakukan pengambilan foto, peserta mencoba untuk mengunggah pada Instagram. Peserta melakukan dengan sangat baik dengan memberikan caption yang menarik pada foto yang telah diunggah (Gambar 4). Selanjutnya peserta mempelajari bagaimana 
melakukan penjualan melalui direct message Instagram dan WhatsApp. Karena peserta masih di bawah umur maka untuk urusan pembayaran diserahkan kepada guru.

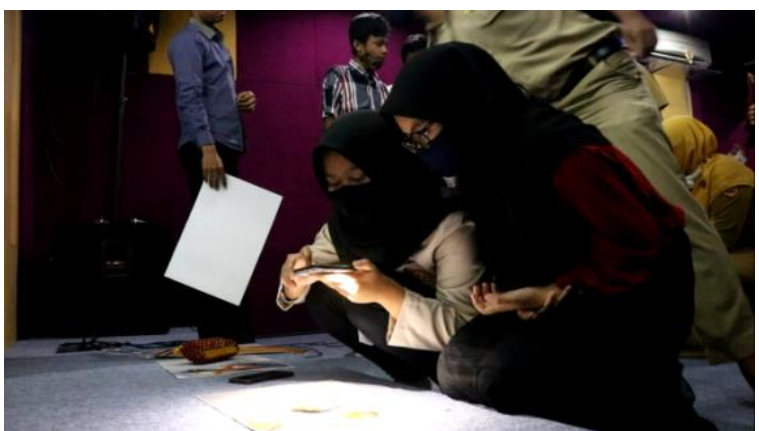

Gambar 4. Peserta melakukan praktik pengambilan foto menggunakan permainan cahaya

Proses selanjutnya pemberian tugas. Dalam pemberian tugas ini, fasilitator meminta kepada para peserta untuk melakukan praktik di rumah maupun di sekolah dengan tetap mematuhi protokol kesehatan yang sudah ditetapkan. Tugas yang diberikan antara lain meliputi praktik pengambilan foto dengan menggunakan alas foto yang sudah diberikan oleh fasilitator sebelumnya lalu mengunggahnya pada sosial media (Gambar 5).

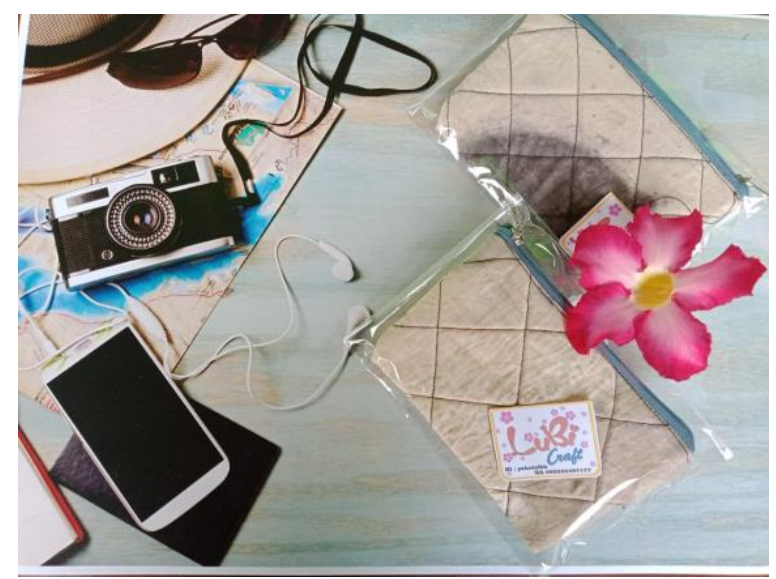

Gambar 5. Hasil foto karya peserta pelatihan

Pada tahap ini dihasilkan luaran karya foto siswa yang sudah sangat baik. Siswa dapat mempraktikkan sendiri di rumah dengan berbekal kamera smartphone dan alas foto serta aplikasi Instagram. Digital marketing membantu karya anak berkebutuhan khusus agar lebih dikenal oleh masyarakat luas. Tidak banyak yang mengetahui potensi yang dimiliki oleh anak berkebutuhan khusus yang sangat besar.

Digital marketing menjadi solusi ketika penjualan langsung tidak bisa dilakukan saat ini terlebih karena pandemi Covid-19 yang tidak kunjung usai. Siswa yang belajar di rumah tentunya juga merasakan kejenuhan yang luar biasa sehingga dengan adanya pelatihan seperti ini menggali kembali kreativitas yang mungkin sempat hilang karena diberlakukannya belajar di rumah.

Selain itu siswa juga dapat menjadikan ini sebagai pelatihan membangun kepercayaan diri. Dikatakan percaya diri karena siswa belajar untuk lebih akrab dengan teknologi, menggunakannya untuk hal-hal yang baik serta bisa membantu untuk bersosialisasi dengan dunia luar menggunakan cara digital marketing.

Pada pelatihan ini terdapat beberapa faktor pendorong diantaranya adalah: 
1. Keterbukaan informasi terutama dari pihak SLB B Yakut Purwokerto yang menyambut dengan baik rencana pelatihan dengan memberikan informasi tentang acara yang ingin dibuat.

2. Sambutan dari siswa SLB B Yakut Purwokerto yang sangat antusias dengan pelatihan yang diselenggarakan.

3. Adanya feedback yang baik dari pihak peserta setelah mengikuti pelatihan ditunjukkan dengan mengumpulkan tugas yang telah diberikan oleh fasilitator.

4. Terjadinya pandemi Covid-19 sedikit banyak mempengaruhi minat masyarakat yang meningkat untuk membeli produk lokal dengan cara yang mudah yaitu melalui online.

Sementara untuk faktor penghambat sampai saat ini belum bisa ditemukan karena proses konsultasi hingga pelatihan lanjutan bisa dilakukan melalui online.

\section{SIMPULAN}

Kegiatan pelatihan berlangsung dengan baik dan lancar. Peserta pelatihan sangat gembira karena terbantu dengan pelatihan digital marketing ini.

\section{UCAPAN TERIMAKASIH}

Tim fasilitator mengucapkan terima kasih kepada pihak-pihak yang telah membantu, terlibat dan berperan dalam terselenggaranya kegiatan pengabdian kepada masyarakat ini, yaitu pihak SLB B Yakut Purwokerto dan Universitas Amikom Purwokerto.

\section{DAFTAR PUSTAKA}

Abdullah, N. (2013). Mengenal Anak Berkebutuhan Khusus. Magistra No. 86 Th. XXV.

Deputi Perlindungan Anak. (2010). Karakteristik Anak Berkebutuhan Khusus. Jakarta. KPPPA RI.

Efendi, M (2006). Pengantar Psikopedagogik Anak Berkelainan. Jakarta. Bumi Aksara.

Hallahan, D. P., Kauffman, J. M., \& Pullen, P. C. (2009). Exceptional Children: An introduction to special education (1 $1^{\text {th }}$ ed). Boston, MA: Allyn \& Bacon 